\title{
Development of bio-based economy: Entrepreneurial endeavors and innovation across Bulgarian wine industry
}

\author{
Mina Angelova \\ Department of Management and Quantitative Methods in Economics, \\ University of Plovdiv Paisii Hilendarski \\ Bulgaria \\ mina.angelova@,uni-plovdiv.bg \\ Daniela Pastarmadzhieva \\ Department of Political Sciences and National Security, \\ University of Plovdiv Paisii Hilendarski \\ Bulgaria \\ daniela.pastarmadrhieva@uni-plovdiv.bg
}

\begin{abstract}
We are living in a time when the population of the Earth is increasing and the available resources are decreasing. The latter requires the establishment of a smart and sustainable bio-based economy, and the creation of such an economy is tightly associated with the implementation of innovations. Bulgarian wine industry is a sector, where possibilities of innovations related to bio-economy are vast and open. Thus, the current study aims at identifying the entrepreneurial endeavours and the innovations' involvement in the wine industry as a specific sector of the bio-based economy in Bulgaria. The results indicate that there is a potential for the introduction of bio innovations in the wine industry as the producers are willing to implement them. However, currently there are almost no innovations related to the bio-economy and the prevailing innovations in Bulgarian wine industry are the marketing ones.
\end{abstract}

Keywords: bio economy, innovation, knowledge management and entrepreneurship, wine industry, Bulgaria.

JEL Classification: L26, O30, Q57

\section{INTRODUCTION}

Biological resources and ecosystems of the world are limited, thus, innovative approaches are needed to feed the growing population and provide people with clean water and energy. Bio-economy can turn algae into fuel, recycle plastics, produce furniture from garbage or waste, create organic fertilizers from industrial waste and so on. 
The topic of this research corresponds to the most topical issues today. The increase in material wealth and in consumption has led to the need for transformation in the practices of resource use in production, consumption and waste treatment. Furthermore, the resources of the planet are limited and the population of the Earth is steadily increasing, this leads to even more consumption and more wastes. Thus, every scientific attempt to contribute to this topic would be significant and relevant.

The main goal of the current study is to identify the entrepreneurial endeavours and the innovation involvement of the wine industry as a specific sector of the bio-based economy in Bulgaria. The research is focused on the attitudes of managers in accordance with their position as change-driven persons. The data concerning the use of innovations and specific entrepreneur activities in Bulgarian companies from the wine sector were collected through an online survey and in-depth interviews conducted from February to May 2019. The object of the research is management of SMEs wine producers, located in the Plovdiv Territorial Unit, Bulgaria. The subject of the study are innovative practices applied by Bulgarian wine producers and opportunity recognition for the development of bio economy in this region and country.

To accomplish the goal, the following research tasks were carried out:

1) A review of the existing theoretical concepts and studies, regarding the studied topic.

2) Clarification of the concepts and notions.

3) A qualitative survey through unstructured interviewing (in-depth interviews) with a limited number of SME representatives in the wine-producing sector.

4) Systematizing and analyzing the obtained results and identifying key challenges for the innovative activity of SMEs in the wine sector.

5) Discussing opportunities to optimize innovative activity through the use of biotechnologies.

The initial hypotheses of the research are formulated as follows:

1) Bulgarian wine producers are open to implementation of innovations;

2) The most preferred innovations are product and marketing ones;

3) The main reason for implementing innovations is to increase profit.

The article is structured as follows: in the first part different theories, definitions and statements connected with innovations and entrepreneurship are summarized. This becomes the framework for our study and the basis for the second part which presents the research methodology. It is followed by the third part which presents the results of the survey and its statistical analysis. The article closes with conclusions and recommendations for future research in the field of innovations and the overview of opportunities for transformation of Bulgarian wine industry enterprises into bio producers.

\section{LITERATURE REVIEW}

\subsection{The concept of innovation}

All human-made changes that the world witnesses are a result of the tendency to seek something new and different. New ideas in the world do not end, but when these ideas create value, satisfy existing or create new needs, innovation comes about. Good ideas are useless until they are realized. Moreover, in order to be realized, the entrepreneur must intervene and through his vision, pro-activity and sense of measured risk to throw the good idea into a ready-made product.

The term innovation stems from the Latin 'novatio', and translated verbatim 'Innovatio' means 'in the direction of the change". The very concept of innovation appeared for the first time in scientific research in the 19th century. The concept was gained in the early 20th century by Austrian scholar J. Schumpeter (1949), who described the new-generation processes as "creating new combinations" or changes in the development of market and production. According to Schumpeter (1946), the term "innovation" means an 
amendment to introduce and use new types of consumer goods, new production and transport means, markets and forms of organization in production. The end result of the process is creating a new product, service, process, or a form of organization.

We can distinguish several types of innovation depending on various criteria. In the Oslo Manual 2018 (4th edition) the Organization for Economic Co-operation and Development (OECD) gave a new classification of innovations. There are two major groups - product innovation and business process innovation. Product innovations can be innovations of goods and of services. Business process innovations include innovations in production of goods or services, distribution and logistics, marketing and sales, information and communication systems, administration and management and product and business process development (OECD, 2018).

As the scholars pay more and more attention on the general effect of innovations on growth, there are some more focused studies, which aim at examining the role of innovations in certain sectors. Such sector is the wine industry and many authors seek to find the role of innovations on its development.

There are number of factors, which determine the ability of wine producers to utilize various innovations in accordance with the development of bio-based economy. One of the conclusions of the report of Intergovernmental Panel on Climate Change (2014) is that the climate change has its socioeconomic aspects, which need to be assessed. Furthermore, there are some specific aspects, which should be taken into account, namely the sustainable development, the effects on the different regions, risk management, and ability for adaptation.

An example for novelty practice in wine production is the segment of organic wines. Although it is still a small sector, it is growing rapidly (Arthur, 2019). Wine producers are motivated to produce such wines as they possess higher quality, because of the chemicals free land, and because the consumers demand for such products. Among the EU countries, which are the biggest producers of organic wines are Italy, France and Spain. This good practice requires efforts by Bulgarian wine producers to implement such innovations and to become part of the global trends.

Veissiere (2015) gathered data from online media websites and individual wine company websites. Such approach provides the opportunity to have a clearer vision of the overall innovations. Furthermore, it gives information on where the enterprises are located in the wine industry value chain according the innovation tendencies that occur in the global wine market. Thus, it designs the adequacy between them and the existing wine business strategies followed in the industry. The author reaches the conclusion that the marketing strategies of the wine producers does not correspond to the views and expectations of the consumers. The author believes that the growth of such wine companies is undermined by insufficient knowledge of the entrepreneurs on what marketing strategies they should implement.

Muscio, Nardone and Stasi (2013) focus their work on the study of introduction of eco-innovations in the Italian wine industry. They propose indicators of eco-innovations and define two groups - input indicators and output indicators. Input indicators consist of improvement of resource efficiency, reduction of water consumption, reduction of energy consumption. The suggested output indicators include waste management (incl. wastewater management) and gas emissions. Moreover, the results of their empirical analysis give evidence about the characteristics of wine producers, who are more likely to introduce ecoinnovations. According to the results of Muscio, Nardone and Stasi these are larger wine producers (manufactories), which are limited companies or cooperatives (not a sole proprietorship). In addition, these producers are more committed to process and organizational innovations. 


\subsection{Entrepreneurship in Wine Industry and Bio-entrepreneurship}

Over the past decades, the global wine production has undergone fundamental changes, characterized by the new shape of competition that has pushed towards the application of strict rules and techniques for wine standardization, processes optimization, certifications and cost reduction in order to increase the international competitiveness. As a result, "big players have been obliged to leave non-core businesses and run business unit disposals, reinforcing their attention exclusively on premium brands" (Veissiere, 2015) while many small wine business owners are questioning about the usefulness of innovating. In many cases, the small growers have been growing grapes and making wine for years and passed down for generations in the family. Fortunately, many young producers are aware that innovation creates value but in line with this statement, efforts need to be made towards new ways of entrepreneurship.

The Republic of Bulgaria is situated in South-Eastern Europe, located in the east part of the Balkan Peninsula. Its uniqueness is hidden in the balanced combination of incredible nature, black sea strip of wonderful beaches, beautiful mountains for summer and winter tourism, rivers and so on. Besides all these natural resources, Bulgaria is a country with poorly developed economy and is far behind the economics of other countries in the European Union (Davidkov and Yordanova, 2015). In terms of Global Competitiveness Index, Bulgaria also lags behind the majority of the EU member states (Angelova and Nikolova-Alexieva, 2018) but data of The Global Competitiveness Report 2018 presents a positive tendency and the country takes 41 st place of 140 countries. Bulgaria still poorly utilizes the advantages of the global process for raising the national competitive power, realizing an economic structural reorganization and modernization of the technical manufacture (McMillan and Woodruff, 2002).

Bulgaria was from those nations that had little or no experience with market economy because communist planning and industrialization were contemporaneous. In line with Estin and Mickiewicz (2010) as a result, laws and market supporting institutions had to be developed from scratch. Bulgaria started the transition process in 1989 and was one of the first transition countries to adopt a new constitution. The preparation of the accession of Bulgaria to the European Union had a positive influence on the environment for enterprise development (Angelova \& Nikolova-Alexieva, 2018). In 2007, after fulfilling economic and political criteria, Bulgaria joined the European Union. The transition created many opportunities for entrepreneurship in transition countries and entrepreneurship became an important factor for the transition from centrally planned to market economy (Dana \& Ramadani, 2015). A recent study of the Bulgarian entrepreneurial ecosystem shows that besides the challenges, that the ecosystems possesses, it has become more and more dynamic one. It is mostly valid for the start-up ecosystem that is emerging an increasingly dynamic, active and open-minded community with a strong taste for innovation in the ICT industry (Hadjitchoneva, 2018). Furthermore, Bulgaria has better performance than Romania in the area of innovations, technology readiness and macroeconomic environment. (Hadjitchoneva, 2017)

In summary, during the last decade, the Bulgarian economy has achieved macroeconomic stability and growth. Various measures were implemented in order to improve the environment for doing business especially for SMEs. Entrepreneurs exploit new opportunities and are associated with disturbing the market equilibrium. They often revolutionize industries overturning long-established technologies, business models and dominant companies (Hisrich, Peters and Shepherd, 2017). In order to do so, they innovate and take risks.

A definition of Bio-entrepreneurship (Brenner \& Patzelt, 2008) states that it is the integration of two different disciplines: science (bio) and entrepreneurship. Actually, it is the smoothest sailing of innovation from academia to industry. Unlike other businesses, Bio-entrepreneurship is entirely academia-powered. It can also be defined as "the use of biological entities or any idea, related to sciences for purpose of acquiring 
profit and establishing a business". Bio-entrepreneurship is the sum of all activities necessary to build an enterprise that creates, build and commercialize the biotech products.

In the bio-based economy lays a big opportunity for Europe. Locally produced bio-based feed-stocks rather than imported fossil resources are used to produce materials, chemicals, energy, creating a new knowledge and technology intensive economy with high employment potential and with reduced environmental impact. A rather significant aspect of the topic is that the national policies about the natural resources may affect in various ways the standard of living of the countries' residents (Sakal, 2015). A study by Urban et. al. (2018) takes a closer look at the global market for bio-based products and resources and its interactions with agricultural and food markets. In particular, it describes the effect of increasing demand for bio-based products on market prices and thus the quantity of agricultural resources demanded and supplied. The OECD (2012) defines bio-based products as goods excluding food and feed that are "composed in whole or in significant parts of biological products, forestry materials, or renewable domestic agricultural materials, including plant, animal or marine materials". They recommend that members should "develop and implement national frameworks for assessing the sustainability of bio-based products that take into consideration their environmental, economic and social impacts throughout the whole life cycle of bio-based products".

\section{METHODOLOGY}

The current research presents the results of the first two phases of the empirical research. The third and final step is a qualitative data collection through a structured interview, which is to be done. The results of the first two phases were meant to lead to methodological clarification and provide some indicative data.

The conceptual framework from interviews to surveys is bridged by pre-testing the various concepts with expert advisers (incl. university professors, $\mathrm{PhD}$ students, wine technologists, etc.). This creates a threephase data collection process that spans the different ideas, different methods, and different samples of respondents to create a unified picture of Innovation and Entrepreneur endeavours for Bioentrepreneurship development.

\subsection{Phase one: Concepts refinement}

The first phase of data collection was a content validity assessment exercise undertaken by professors and $\mathrm{PhD}$ students. This exercise was described by Hinkin and Tracey (1999) and was used to help determine the appropriate structure and wording of the Innovation and Bio-entrepreneurship concepts. After examining where potential item confusion might exist and discussing this subset of items with faculty advisers, the subset of items was re-evaluated. This refining step produced the finalized questionnaire next employed in the third phase.

For this exercise, professors and doctoral students from Bulgarian universities (i.e. University of Food Technologies, Plovdiv; University of Plovdiv Paisii Hilendarski; University of National and World Economy, Sofia; University of Ruse Angel Kanchev, etc.) were selected to participate. Previous researchers have indicated that professors and students are acceptable for this kind of exercise because of their expected intellectual capability to distinguish between items and various theoretical construct definitions (Hinkin \& Tracey, 1999; Schriesheim, Powers, Scandura, Gardiner, \& Lankau, 1993).

An email requesting participation in the exercise was sent out to the professors and doctoral students. The email list consisted of approximately $10 \mathrm{PhD}$ students at various stages in the doctoral program and 15 professors of Economic disciplines. The rating exercise consisted of displaying a single questionnaire item along the top of the page with all of the dimensional definitions arrayed in rows. The respondents were asked to rate on a scale from 1 to 5 how much each item was captured by or associated with each dimensional 
definition. The preliminary survey given to the professors and $\mathrm{PhD}$ students for the exercise contained 14 questions. The exercise was administered entirely online and was developed using the online survey software. The respondents were presented with a randomized ordering of the items to avoid order effects.

MacKenzie et al. (2011) suggest that in addition to the dimensions of interest, the rating exercise could include the definitions of related constructs/dimensions in order to help evaluate the discriminant validity of the items. In other words, the rating exercise provides an opportunity to evaluate whether the questionnaire items unintentionally overlap with existing constructs. As a result, there were a total of eight dimensional definitions provided in the exercise to distinguish between over 20 items. 17 responses (almost $75 \%$ response rate) were acquired over a 13-day period. All of the respondents answered all of the questions.

\subsection{Phase two: In-depth interviews}

Based on data of the National Statistical Institute of Bulgaria as of April 28, 2019 in the Plovdiv Territorial Unit operate 36 SMEs in wine industry. Of them 25 are micro with up to 9 employees; 10 are small (from 10 to 49 employees) and there is one medium-sized enterprise (from 50 to 249 employees). (National Statistical Institute, 2019). We selected a potential pool of 10 managers to contact for interviews based on our strongest personal relationships. All of the managers were contacted throughout April 2019, of which 5 agreed to be interviewed. These managers included a diverse collection of men and women from the wine industry. These managers are company founders or owner-managers leading SMEs from 5 to 250 employees. The managers in this phase were selected for their expertise and knowledge in order to explore the motivation for Bio-entrepreneurship domain in-depth.

The data collected in this phase consisted of in-person verbal interviews that lasted an average of 1 hour. All but one of the interviews was conducted at the offices of the companies. One interview was conducted via Internet-enabled video chat (the manager was in her office) due to scheduling reasons. These interviews generated numerous nuanced and insightful opinions into applied innovation strategies and entrepreneurial endeavours for Bio-entrepreneurship development.

Thus, we asked the managers about the proposed model with a focus on innovation and entrepreneurial knowledge and we got their overall feedback and insights into the concept of Innovation and Bio-entrepreneurship. Managers were asked a series of questions to establish the type and origin of their business, their personal background and experience with management and entrepreneurship, and then questions dealing more specifically with applying Innovation and motivation for Bio-entrepreneurship. We asked a broad range of innovation questions and used these data to both compare and contrast the fundamental concepts of the proposed innovation performance model.

Each of the managers was interviewed using semi-structured interview techniques where a series of questions were developed in advance. Follow-up prompts or questions were asked where there appeared to be more insights to gain. The interview questions began with "grand tour" type questions about the origin of the business, the respondent's involvement, and the original opportunity.

Questions about the hiring of early stage employees and the development of innovation at the organization were also asked. The interview then focused on general questions about the proposed conceptual dimensions (e.g., Type of innovation, Entrepreneurship endeavours etc.). It finished with a discussion of any final thoughts the respondent might have on the innovation performance in general, such as how it had changed over time and what future innovation concerns he or she might have. 


\subsection{Phase three: Structured interviews}

The third and final phase consists of the deployment of a questionnaire to a number of organizations in order to survey Innovation performance and Entrepreneurial endeavours more broadly. This part of research design is planned to be realized in future.

\section{EMPIRICAL RESULTS AND DISCUSSION}

The questionnaire about the concept's clarification consisted of 6 general questions, regarding the sex, age, education, area of research, scientific interests and years of research activity. The respondents were also asked to evaluate on the scale from 1 to 5 to what extent a suggested definition corresponds to a certain concept as 1 means "it doesn't correspond at all" and 5 is "it totally corresponds".

Among the scholars, there were 11 women and 6 men. Most of the respondents were between 31 and 40 years (10). There were also 3 respondents between 41 and 50 , followed by 2 , who were under 30 years. There were two respondents over 50 years. Six of the respondents were doctoral students and the others were university professors. Eleven of the group have research experience under 10 years. There were two, whose experience is between 11 and 15 years, two with scientific experience from 16 to 20 years and two of them have been doing scientific research for over 20 years.

In our questionnaire we studied eight concepts - innovation enthusiasm, adaptability to innovative practices, cohesion, support for training and development, promoting innovation/change, support from management, working discretion/autonomy, boundaries of bio-entrepreneurship.

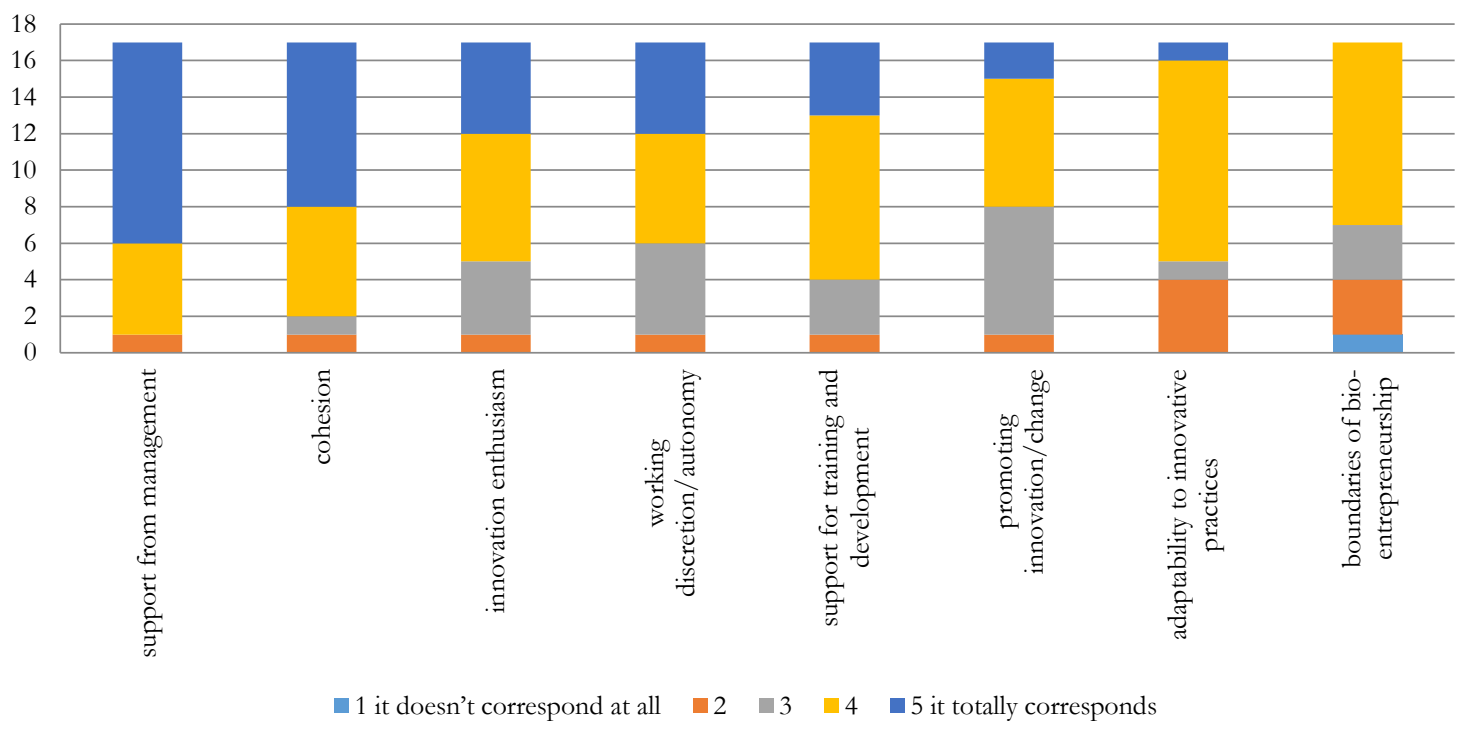

Figure 1. Opinions on the studied concepts

Source: Own data

On the basis of the received opinions we believe that the definitions can be grouped in three groups 1) definitions with no refinements; 2) definitions, which need slight refinement; 3) definitions, which need to be reworked to some degree.

In the first group, we have two concepts with their definitions. The definition for the concept support from management is the most approved one. This definition is "the willingness of senior management to facilitate and encourage entrepreneurial behaviour, including supporting innovative ideas and providing the 
resources needed for employees to start entrepreneurial action". Over $50 \%$ of the respondents agreed that the definition provided for the notion of cohesion is the right one, namely "a model of values, perceptions and practices for connecting and engaging members of the organization with each other and with the organization, regardless of the circumstances", is acceptable for the experts.

There are three concepts and their relevant definitions, which have rather close results. We put them in the second group - definitions, which need slight refinement: innovation enthusiasm, working discretion/ autonomy and support for training and development,

The third group consists of definitions, for which the answers are to some extent controversial and we believe that it is better to rework them slightly. These are promoting innovation/change, adaptability to innovative practices and boundaries of bio-entrepreneurship.

After consulting with faculty advisors and several $\mathrm{PhD}$ students who provided feedback on the exercise, we decided to seek additional resources on survey design as well as innovation questionnaires. This consultation was motivated by the results of Phase Two, namely the observed confusion between items and their resultant ratings, compared to their expected ratings. We were directed towards classic questionnaire item development resources (e.g., Converse \& Presser, 1986; Spector, 1992) for tried-and-true guidance on structuring clear, unambiguous, items that conceptually accessible for a varied respondent audience.

The purpose of revisiting and revising the items was to retain the same meaning and intent as the original iterations but with enhanced clarity and conciseness. This process was also guided by patterning the structure of the items after a different and far more coherent set of published innovation items.

The next phase of our empirical study, namely in-depth interviews among SMEs wine producers from Plovdiv region gave us very interesting data. Furthermore, it gave us some valuable ideas on the improvement of our methodology. As we have only 5 respondents, we will not focus on the demographic data, but only summarize it. Among the interviewed managers, there were three women and two men. They were from different age groups, namely up to 30 years, 31-40 years and 51-60 years. All of the respondents have the same educational degree - Master Degree. Nevertheless, they have different number of years of experience - 1-5 years, 11-15 years and one of them has over 20 years of experience. They all belong to small or medium-sized enterprises, who work in wine production or vine growing, winemaking and distribution. All of the enterprises work on national and European markets and two of them declare that they operate on world markets. All of the enterprises are with private ownership.

As concerns the innovation activity four of the enterprises declared that they implement innovations and the fifth plans to start. We asked the entrepreneurs if they are planning a transformation in the way they do the business as part of the innovation strategy. Only one selected answer "No". The others plan to make social entrepreneurship, digital entrepreneurship and Bio-entrepreneurship. Such results can serve as evidence for the proclivity of Bulgarian wine producers towards introducing innovation. On one hand, the latter has the potential to enhance the functioning of each enterprise and make it competitive to other EU wine producers. On the other, as the SMEs wine producers introduce innovations on various levels of their companies this can meliorate the results in the whole wine sector in Bulgaria.

Furthermore, the above-mentioned answers give ground to assume that wine industry in Bulgaria indeed has the potential for developing bio-economy as most of the respondents declared readiness to develop bio entrepreneurship. Thus, SMEs wine producers can transform their sector into a key sector for introduction of bio-based innovations.

However, as the level to which the innovation strategies have been implemented in the enterprises there is a variety in the answers. Although there are 2 enterprises, which don't work on the documenting of business processes, the others currently work on the implementation of such system or they describe the processes one by one, when they have time to do it. Such approach is not an effective one and for sure the wine producers need support and in some cases more information and education on the way they have to 
manage the process. As previous studies identify, the companies need an organizational agility in order to answer the changing business environment (Ilieva, Anguelov and Nikolov, 2018). On this topic, a more detailed data is required so that we can first identify the real obstacles and second, to propose the best solution for the problems they have in implementing innovations on various levels.

Nevertheless, the elaboration of an innovation program in enterprises starts with the way of thinking and believes of the high-level managers. Furthermore, they should be convinced that this is connected with the positive development of the company. Thus, one of the most significant questions in our survey was about the expected results from the implementation of innovations. This question is rather important as it show the motivation of the wine producers. To high extent, their motivation can serve as an indicator of their view on the potential role of the innovations in the improvement of their business. The results show that according to the respondents the three most expected benefits of the introduction of innovations are increased satisfaction of the employees, increased efficiency and the enhancement of the competitiveness of the enterprise. The latter are followed by the expectancy for increased satisfaction of the customers (Figure 2).

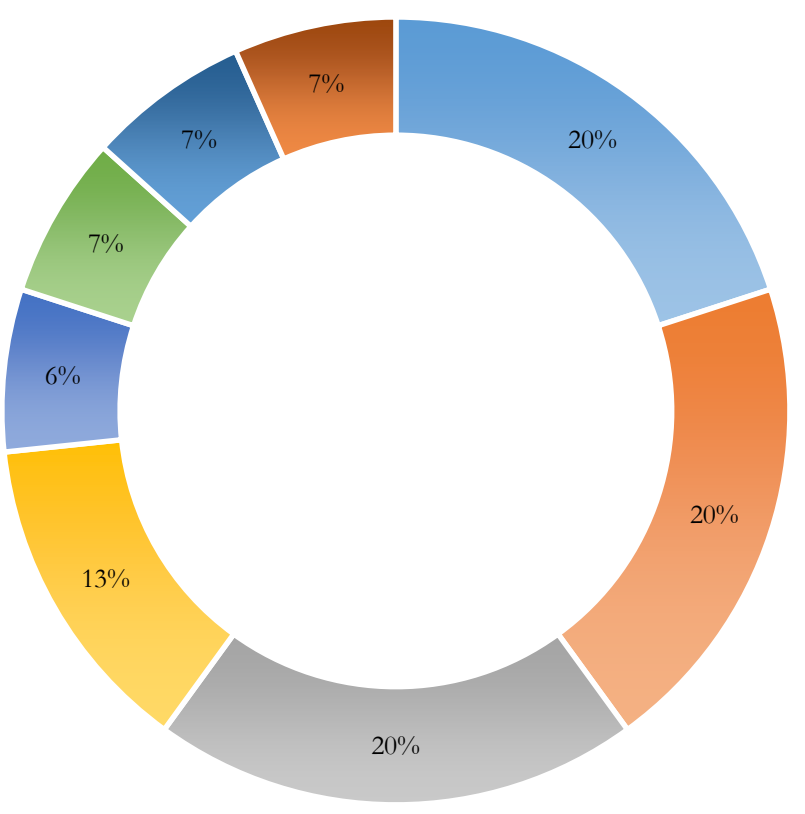

Figure 2. Expected results from the implementation of innovations Source: Own data

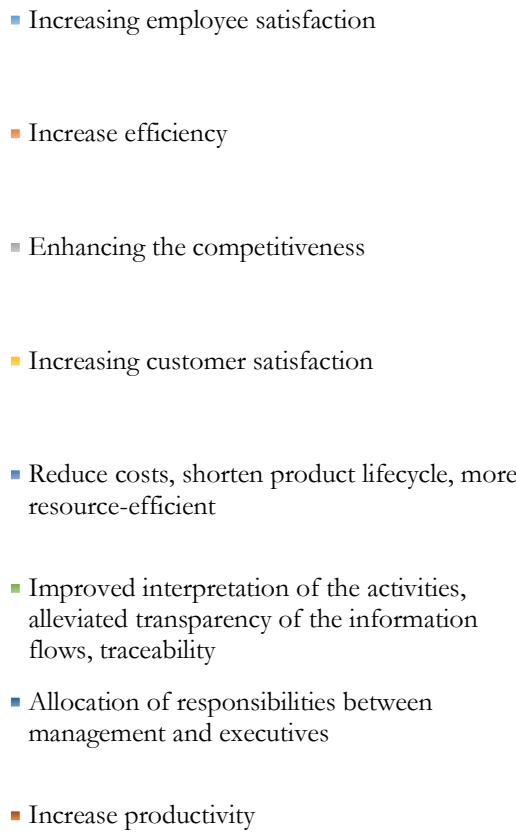

- Allocation of responsibilities between management and executives

- Increase productivity

We believe that this selection of results demonstrates that the focus of entrepreneurs is not just to maximize their profits, but it is in three dimensions. One is the enterprise itself and the increase of its efficiency and competitiveness. The next dimensions are the employees in the enterprise and their satisfaction. The third dimension is the consumers of the products and their contentment with the product. Such results indicate that the wine producers are responsible and reasonable in introducing innovations with care for the future of the business as a whole, of their employees and of the end customers - wine consumers.

Another significant element of our research was to identify how the wine producers understand the notion of entrepreneurial culture. Thus, we asked them how they would describe the essence of the 
entrepreneurial culture of their business. There are five answers, which according to the respondents are the most relevant. The latter consists of the common traditions, values, sense of community, the socialpsychological environment, etc. (Figure 3) Such results show that the entrepreneurs wine producers from Plovdiv region view the entrepreneurial culture of their business as composed of unwritten rules rather than the formal procedures and the formal regulation if the relations in the company. In fact, the prevalence of the informal norms is rather typical for the Bulgarian culture in every area - economic, social and political.
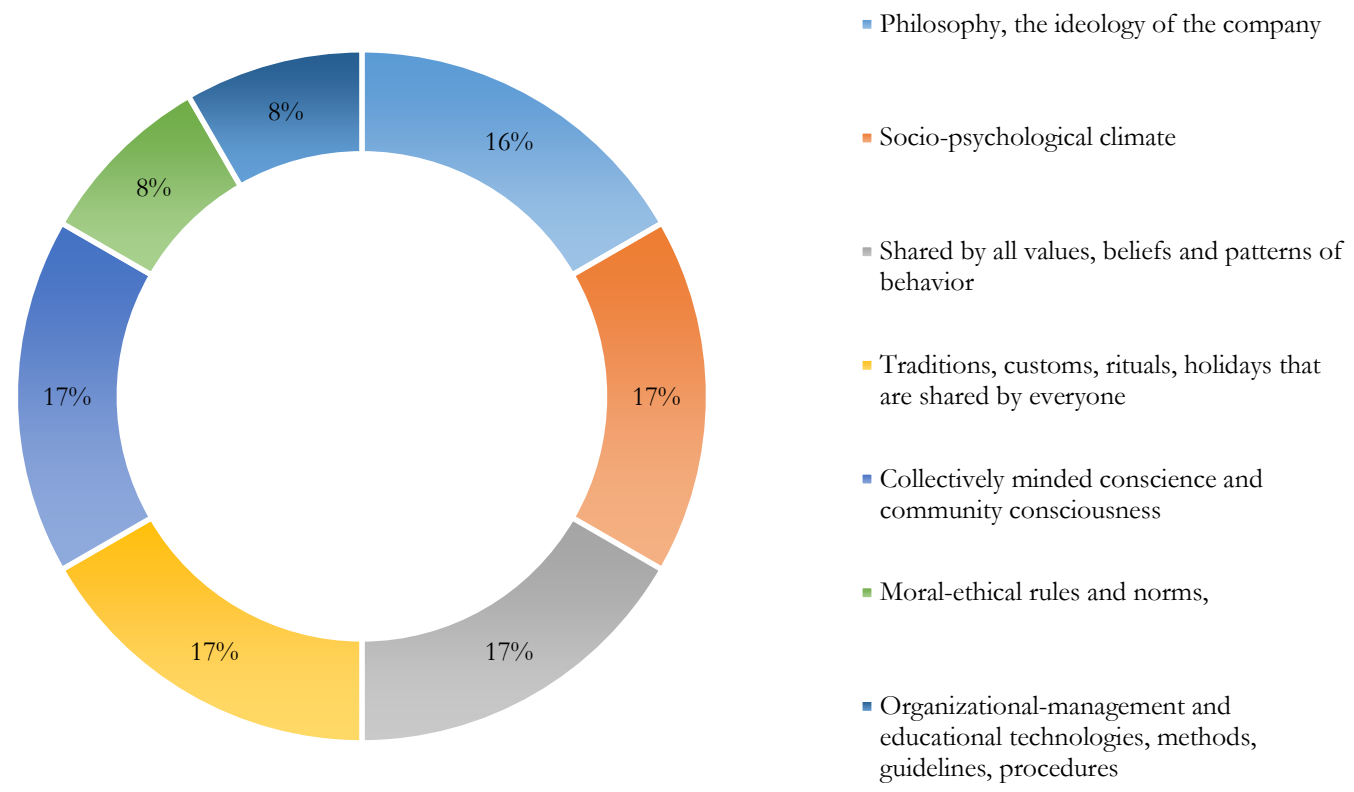

Figure 3. Essence of the entrepreneurial culture of the own business

Source: Own data

Another important issue in our research is the understanding of entrepreneurs of innovation strategy. Thus, we gave them some options and asked them to select those, which according to them correspond to the innovation strategy and culture. There are five answers among eight options, which are mostly selected. Three of them are directly related to the development of the enterprise itself, namely:

- Willingness for better position on the market;

- Increased income;

- Ensuring higher status and competitiveness.

Nevertheless, the entrepreneurs also believe that the innovation strategy is related to a contribution to the overall entrepreneur environment in the country. The selection of this answer indicates the understanding of the wine producers that their efforts in innovation activity may go beyond their own prosperity and can contribute for the development on national level. Furthermore, according to them such strategy includes providing jobs for knowledgeable, capable and motivated specialists from different fields. In fact, currently in Bulgaria the employers have challenges in finding such employees and this constellation may be the reason why the wine producers selected this answer as a possible effect of the implementation of an innovation strategy (Figure 4) 

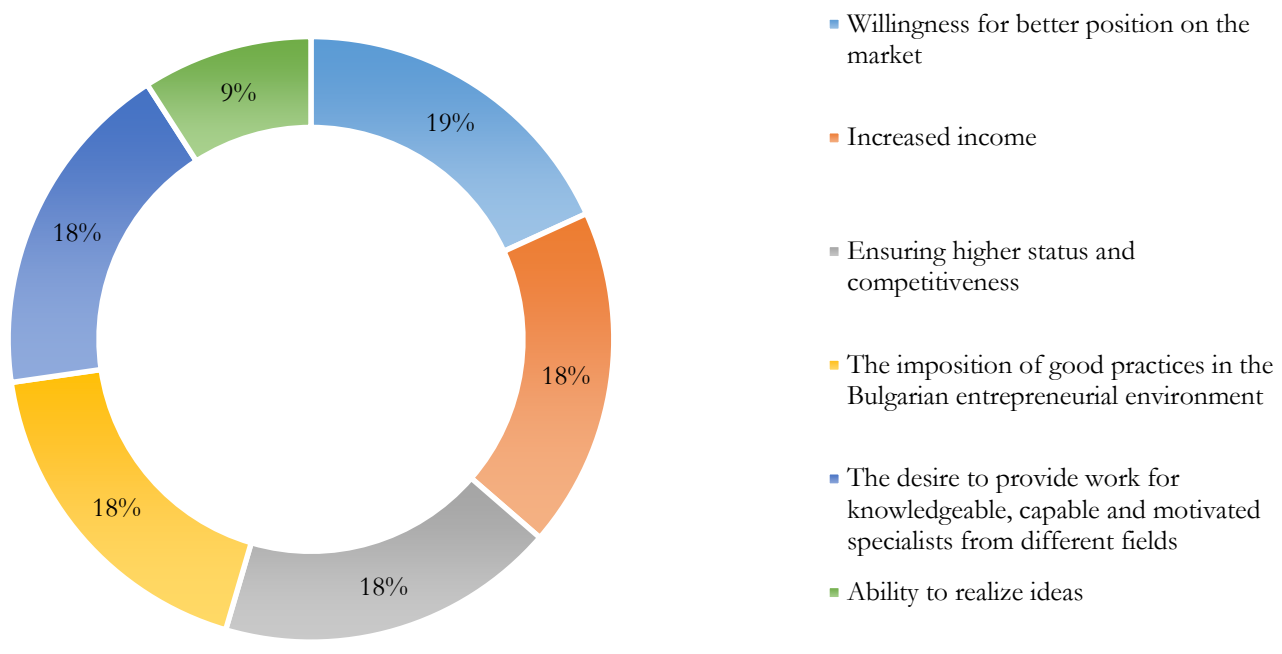

\section{Figure 4. Understanding of innovation strategy}

Source: Own data

In our research on the topic, made by now, we have identified the most commonly implemented innovations in the wine industry. With the last question we wanted to find whether the wine producers from Plovdiv region know about them, implement them or are willing to implement them. Thus, we made a list with 50 possible innovations and asked the respondents to select one of the following answers for each of the innovations:

1) Not applicable to us;

2) We know about this opportunity, but we would not apply it;

3) We know about this opportunity and we would apply it;

4) We apply it now;

5) We applied it in the past.

The results show that there is a group of innovations applied by all of the respondents, namely:

- production of products in price segments of super-premium and ultra-premium;

- refinement of production process,

- increase of brand awareness;

- investment in advertising;

- exchanging production knowledge.

Furthermore, all of them are informed about the option to improve their merchandising and declare readiness to make it.

We also identified another group of innovations, which is widely implemented by wine producers. For these innovations they gave answer "we apply it" or "we know about this opportunity and we would apply it". These are: improvement of varieties, alternative energy sources (photovoltaics), managing relations with suppliers, expansion to new foreign markets, increase the number of distributors in foreign markets, new market promotions, new strategic agreements, new labelling, seek to have rating in expert wine guides, seek to win awards, revision of the organizational routines, extensive use of technology transfer, training activities of the organization, improvement of resource efficiency, reduction of energy consumption, waste management and reduction of gas emissions. 


\section{CONCLUSION}

The SMEs are the engine of the European economies and the same is valid for Bulgaria. The implementation of innovations in such enterprises has the potential to enhance their function in many areas. The wine industry is one of the main sectors of Bulgarian economy and that is why the improvement of its functioning is rather significant. The last 15-20 years are a period of enormous investments in the Bulgarian wine sector, which has become the most competitive one from the Bulgarian food industry. It consists of more than 50 cellars. A research of B. Georgiev (2019) states that the wine production sector is more than $80 \%$ export oriented and is a food industry leader with its $30 \%$ share of export revenues from EU market. The Europe has $60 \%$ of world vineyards measured by the area of the vineyards. EU has $45 \%$, while Bulgaria and Chile jointly share 17 -th world position.

The major wine export is based on the well-known French grape sorts. The Bulgarian national vine sorts like Mavrud, Merlot, Dimyat, Pamid, Gamza, Melnik, etc. have very big potential, which recently is used to the very limited extent. The vineyard renovation with unique and quality Bulgarian vine sorts should become a first national priority. There are Bulgarian trade wine marks like "Kadarka", "Manastirska Izba", "Sofia" well known for ages in some EU and CEFTA countries. Their status is not quite clear in case of their use by different Bulgarian exporters. There are some complicated and inefficient administrative procedures like issuing of export forms VI1 for EU. There is also excise on the wine, which is not the case in most of world wine producing countries.

In the context of bio innovations, the Bulgarian wine industry makes efforts according to correspond consumers' demands for top quality wines and food safety, providing eco-friendly production methods and winegrowers technical needs in a climate change background. Furthermore, the endeavors are forced on the next three levels:

At the plant level, to improve and design agricultural practices (canopy management, irrigation, fertilization, training systems, and pest and disease control) with the aim of maximizing berry quality, durable resistance to pests and diseases, and adaptation to climate change.

$\checkmark$ At the vineyard level, to design, develop and test innovative agronomic systems integrating new agricultural practices and taking into account the variability of constraints met by European vineyards grown under a wide range of environments.

$\checkmark$ At the breeding level, to diversify grapevine varieties with regard to desirable adaptive traits building on tools and knowledge developed through international breeding genomic initiatives.

The process of restitution of the land has to be significantly accelerated and functioning land market developed in order to open the way of planting new vineyards and provide necessarily quantities of grape for wine. State has to accelerate land restitution and creation of land market. Practical facilitation of export procedures and trademarks issues is of great importance for wine producers.

The results of our survey with experts helped us to refine the meaning of some of the concepts that we use. Such refinement will help us to increase the scientific quality of the formulation of the final version of the questionnaire for the wine producers in Plovdiv region.

The in-depth interviews gave us valuable information and helped us to understand better the replies of our respondents. These interviews are the ones, which gave us the direction for improvement of some questions and some of the suggested answers. We found out that our survey gave the respondents ideas for new innovations in their enterprises. In line with this, we decided in the final version of the questionnaire to include question if the suggested innovations gave them an idea what they might implement in their enterprise. The results of in-depth interviews proved the first hypothesis based on the clear understanding of high-level managers that the use of innovation in wine production, its management and marketing is a key factor in achieving competitiveness and an instrument for the internationalization of the sector. 
The results of our research indicate that wine producers in Bulgaria invest or are ready to invest in product, marketing and to some extent in bio innovations. To high extent this proves the second hypothesis stated that Bulgarian SMEs from wine industry are more likely to implement product and marketing innovations.

The third hypothesis is partially confirmed as the wine producers see the aim of the innovations not only as a tool for increase of the profits, but also the increase of its efficiency and competitiveness, employees' satisfaction and the consumers' contentment with the product.

As the main goal of our research was to identify the entrepreneurial endeavours and the innovation involvement in wine industry as a specific sector of the bio-based economy in Bulgaria, we can make some specific conclusions. Currently, none of the respondents produces Bio grapes or wines and only one of them intents to do so. Nevertheless, some of them declared readiness to implement solar and photovoltaic energy sources. As concerns the bio packaging, it seems like that this is innovation that can be implemented, because respondents implement or are ready to implement such innovation, and there is only one wine producer, who says that he/she would not apply it. A positive indication is their readiness to improve resource efficiency as all of them apply or are willing to apply such innovations. Thus, Bulgarian wine production can be more bio-oriented as concern the will and efforts of the entrepreneurs.

As a conclusion, this article discusses the initial steps to develop a valid and reliable instrument to assess innovation performance and entrepreneurial endeavours. Although the results that were reported here should be regarded as a preliminary step in developing an instrument to assess motivation for Innovation and Bio-entrepreneurship development, the results are encouraging. Nevertheless, this effort sets the stage for a considerable research agenda. It provided a framework for further exploration of the specific factors that influence innovation strategies and a basis to build reliable and valid scales to measure those factors.

\section{ACKNOWLEDGEMENT}

The current article is part of a project KP-06-M25/5/17.12.2018, financed by National Science Fund of Bulgaria, Ministry of Education and Science.

\section{REFERENCES}

Angelova, M. (2019). Possibilities for Social Entrepreneurship in Wine Industry: an Exploratory Approach, International scientific journal Science. Business. Society., 4(1), 15-18.

Angelova, M. \& Nikolova-Alexieva, V. (2018). Business climate and preconditions for reviving the Bulgarian industry, International Scientific Journal Machines. Technologies. Materials, 1(2), 69-72.

Arthur, R. (2019). The organic wine world is in full expansion mode - and shows no signs of stopping, https://www.beveragedaily.com/Article/2019/02/08/, Retrieved April 19, 2019.

Dana, L-P. \& Ramadani, V. (2015). Family Businesses in Transition Economies Management, Succession and Internationalization, Cham, Switzerland: Springer International Publishing AG.

Davidkov, T. \& Yordanova, D. (2015). Enhancing SME internationalization in a transition economy: the role of internal factors, International Journal of Latest Trends in Finance \& Economic Sciences, 5(3), 945-956

Georgiev, B. (2019). Competitiveness of the Bulgarian Wine Industry, online available on https://ime.bg > download [01.12.2019]

Hadjitchoneva, J. (2017). Comparative Analysis of Entrepreneurship in Bulgaria and Romania. In: Iskra ChristovaBalkanska \& Eduard Marinov (Eds) Bulgaria and Romania: Country Members of the EU, Part of the Global Economy (pp 71-92), Sofia: ERI-BAS Books.

Hadjitchoneva, J. (2018). Systemic research of entrepreneurship in Bulgaria. Economic Thought, 4, 61-83. 
Hinkin, T.R., \& Tracey, J.B. (1999). The Relevance of Charisma for Transformational Leadership in Stable Organizations http://scholarship.sha.cornell.edu/articles/666 Retrieved April 20, 2019

Hisrich, R., Peters, P., \& Shepherd, D. A. (2017). Entrepreneurship (10th ed.), New York: McGraw-Hill Education

Ilieva, R., Anguelov, K. \& Nikolov, M. (2018) Structural Approach for Organizational Agility Path Analysis, Proceedings of the 44th International Conference on Applications of Mathematics in Engineering and Economics, doi:10.1063/1.5082146

IPCC/GIEC (2014). Climate Change 2014: Synthesis Report, Contribution of Working Groups I, II and III to the Fifth Assessment Report of the Intergovernmental Panel on Climate Change [Core Writing Team, R. K. Pachauri and L. A. Meyer (eds)], IPCC, Geneva.

MacKenzie, S.B., Podsakoff, P.M., \& Podsakoff, N.P. (2011) Construct measurement and validation procedures in MIS and behavioral research: integrating new and existing techniques, MIS Quarterly, 35(2), 293-334.

McMillan, J., \& Woodruff, C. (2002). The central role of entrepreneurs in transition economies, Journal of Economic Perspectives, 16(3), 153-170

Muscio, A., Nardone G., \& A. Stasi (2013). Drivers of Eco-Innovation in the Italian Wine Industry, In U. Rickert \& G. Schiefer, System Dynamics and Innovation in Food Networks (pp 344-360), Bonn, Germany: Universität BonnILB Press.

National Statistical Institute, Infostat, April 2019

OECD (2012). Recommendation of the council on assessing the sustainability of bio-based products http://webnet.oecd.org/OECDACTS/Instruments/ShowInstrumentView.aspx?InstrumentID=283\&Instru mentPID=298\&Lang=en\&Book=False 17 July 2012 - C(2012)112 - C(2012)112/CORR1 Retrieved April 19, 2019

OECD/Eurostat, Oslo Manual 2018: Guidelines for Collecting, Reporting and Using Data on Innovation, 4th Edition, The Measurement of Scientific, Technological and Innovation Activities, OECD Publishing, Paris/Eurostat, Luxembourg. https://doi.org/10.1787/9789264304604-en, 2018

Patzelt, H. \& T. Brenner (2008) Handbook of Bioentrepreneurship (International Handbook Series on Entrepreneurship 4), New York: Springer-Verlag.

Sakal, H. B. (2015). Natural resource policies and standard of living in Kazakhstan, Central Asian Survey, 34(2), 237-254;

Schriesheim, C. A., Powers, K. J., Scandura, T. A., Gardiner, G. C., \& Lankau, M. J. (1993). Embedding Ethical Leadership within and across Organizational Levels. Academy of Management Journal, 55 (5), 1053-1078.

Schumpeter, J. A. (1946). The Future of Private Enterprise in the Face of Modern Socialistic Tendencies, Comment sauvegarder l'entreprise privée.

Schumpeter, J. A. (1949). Economic theory and entrepreneurial history, in R. R. Wohl (Ed.) Change and the entrepreneur: postulates and the patterns for entrepreneurial history (pp 63-84), Cambridge, Massachusetts: Harvard University Press

Urban K. et al. (2018). Markets, Sustainability Management and Entrepreneurship. In: Lewandowski I. (ed.) Bioeconomy (pp. 231-286), Cham, Switzerland: Springer International Publishing AG .

Veissiere, D. (2015). How MBA programs help the wine producers to innovate creating new employments? BIO Web of Conferences 5, doi:10.1051/bioconf/20150503006, published by EDP Sciences 